\title{
Information Technology and Democracy. Chances and Challenges
}

\author{
Waldemar Czajkowski ${ }^{1}$
}

1 Silesian University of Technology, Gliwice, Poland; wczajkowskil@polsl.pl

\begin{abstract}
We live in the time of profound transformations commonly labelled with the word "globalization". The rise of one ecological-technological-social system encompassing our whole planet is an important element of these processes. Solving big global problems demands knowledge of two complementary sorts: on the one hand - going "in depth", on the other - going "in breadth". The present paper assumes the second (in a sense: philosophical) perspective. It tries to analyze some relations between the development of technology (IT) and the development of democracy. The notion of democracy, its various forms and axiological reasons for it are considered first. In the subsequent chapter different consequences (both positive and negative) the IT development has for contemporary democracy are discussed. In the next chapter the evolutionary nature of the technological development is debated as well as the question of (democratic) control of this process. The development of Artificial General Intelligence is presented as a challenge for democracy
\end{abstract}

Keywords: 1; globalization, 2. participative democracy, 3. deliberative democracy, 4. Collective decision-making, 5. human nature

\section{Introduction}

There is rather common agreement that we have lived for some decades (at least) in the time of globalization. But virtually all other - more or less specific - questions concerning globalization (its "essence", its temporal dimension, its "positive" or "negative" character...) give rise to many - sometimes very hot - debates. Due to the subject of this paper I cannot discuss, even very briefly, these issues. (A very good systematic overview give (Scholte 2005; Jones 2007).) Nonetheless, I would like to formulate a declaration: Many interpretations of globalization should be viewed as complementary rather than opposite. In particular, an interpretation of globalization I am going to present in the next passage is to be viewed not as alternative to those already formulated but as a supplement to them. Or, to put it in different words, as a characteristic of an aspect of globalization.

Globalization, viewed from the perspective assumed here, can be regarded as a process (in the second decade of the $21^{\text {st }}$ century - rather advanced) of the development of a single, encompassing the whole Earth (Tom et al 2013), ecological-technological-social system. (Bauer 2009) It is also assumed that this system is "very complex"; to put it in other 
words - it is strongly non-linear system: in the dtrict, mathematical sense of the word (Mainzer 2004). Two points should be made (each of them would might be a subject of a separate paper or even a book): Firstly, the development of information technologies has been one of the main factors determining (in various ways: sometime direct, sometime mediated) the process of globalization. Secondly, the more our planet manifests (due to human activities) its systemic character the more it should be regarded as a common good of all humanity: a common property that should be commonly governed. The last claim entails the problem of (global) democracy. (Stern 2009)

One issue related to globalization requires a somewhat longer discussion: For the last few decades (let's take the year 1972 - the year in which the "Limits to Growth" Report to the Club of Rome was published, and the Stockholm Conference was held - as a symbolic starting point) many visions of possible crises and catastrophes (self-destruction including) have been formulated. The evaluation of the validity of these visions is, in my opinion, very complex and difficult (Yudklowsky 2008). In whatever way this problem would be solved, one point seems to me undisputable: the very possibility of a profound crisis of the global system is not excluded. (Wiener 1978, Wilczek 2008) Even if the risk (probability) of such a crisis (do we know satisfactorily how to estimate it?) is "very low" (but what does mean the term "low" if the future of all humanity is at stake?) - we should take this possibility into account. And if we do it, we should accept that we all are responsible for our common future - for the future of the global system of which we are a part. And if we accept this responsibility, we should be interested in understanding this system (its structure and dynamics) and, in particular" the role we play in it. But do we possess adequate intellectual instruments that would help us to understand this system? No simple answer is, to my mind, possible. Briefly put: a lot of work has been but still (much?) more remains to be done (Lundstrom and Wong 2013; Stern 2010; Lomborg 2007; ).

Our global intellectual situation is, at least from a point of view, paradoxical: The growth of knowledge humanity has at its disposal has been for the last five centuries very great, and over the last two centuries or so - just immense. The development of science has accelerated, and during the last few decades (say, after $2^{\text {nd }}$ World War) its exponential character has become clearly and evidently noticeable. And saying about the exponential growth of science I mean not only the number of discoveries, theses and theories... I mean also the increase of the number of scientists, of books and journals, and - last but not least - of scientific disciplines.

One cannot doubt that this development has brought about many positive results. But it has had also some negative consequences. Their systematic analysis is to be undertaken by historical epistemology or sociology of knowledge/science. It cannot be even sketched here. But at least one issue is to be mentoned here: It seems that today - just due to the processes described above - to develop a coherent science-based world-image is today more difficult than it was, say, one hundred years ago. And we lack such an image just in the epoch in which we need it badly - more urgently than ever. Not only for purely 
intellectual reasons, but - first of all! - for very practical ones: reasons implied by globalization and the responsibility for our common future.

How to overcome this situation (some call it "intellectual crisis")? I am convinced that it is philosophy that has an important role to play here: It is the task of philosophy (of course, to be realized not in separation from particular scientific disciplines, but through active collaboration with them) to offer such world-image(s). For two important reasons, at least. Firstly, unlike individual scientific disciplines, philosophy has no defined (and limited) domain; or, alternatively, it might be said that its domain comprises "everything"(including not only the actual but the potential also). Secondly, philosophy is both descriptive and normative: it tries to say not only what the world is like, but also what it ought to be. (It might be added here that, due to centuries-long ongoing debates, philosophers are particularly aware of the complexities of the relations between various types of discourses, in particular - descriptive and normative.)

The present paper - though it undertakes a very limited number of issues (thus it is very distant from any overall world-image) - is intended as a philosophical text: First, it discusses some problems apart from their "disciplinary affiliations": on the one hand these issues that are discussed in political theory or legal studies, on the other - those debated in such fields as social studies of technology or media studies. Second, this paper formulates not only descriptive but also normative (or axiological/evaluative) propositions. (Kuzior and Zozul'ak 2019; Przybylska-Czajkowska 2019a)

The central question of this text can be formulated in a simple way: In which ways information technology actually influences (both positively and negatively) democracy and vice versa, in which ways could influence, and in which - ought to? (Sclove 1995, Caplan 2008)

\section{On democracy}

Democracy - both as a practice and as an idea - is a huge subject. Thus I am not going to present any, even very concise, overview of all important problems that could be grouped under this heading, but I will limit myself to a small number of issues - to those which will be relevant for the further considerations that will be conducted in the next two chapters.

The term "democracy" was created already in ancient times (Plato, Aristotle) as a characteristic of some states. In the $20^{\text {th }}$ century the scope of this notion was considerably enlarged: it can be today referred to political parties, factories, universities or even churches. It might even have some sense to speak about democratic relations in families (Przybylska-Czajkowska 2019c; Courpasson 2017). 
I not only accept this broad understanding of the notion of democracy but I consider it to be theoretically useful and inspiring. However, I will focus mainly on democracy as a characteristic of states, sub-state territorial units, or multi-states organizations (such as European Union). Alternatively, it could be said that the word "democracy" is to be referred here to such groups as nations or local communities. (Kuzior 2014)

I am not going to present any definition of democracy: in my opinion, good definitions can be formulated only in the context of a theoretical system (i.e. a collection of concepts and theses "sufficiently logically similar" to mathematical or physical theories); unfortunately, still, social sciences do not rather dispose any such system. Thus, it will be - to my mind - better to characterize the notion of democracy discussing a number of ideas connected in this or that way with this very notion (instead of formulating a "definition" of it)

The most general concept we should, I think, start with is that of (rational) decisionmaking. This notion is so widely used in various disciplines (economics, psychology, sociology...) that no comments seem to be necessary here.

A step is to be made now from the concept of decisions being undertaken by individuals to group (collective) decision-making. As it is in the case of individual decisions also group decisions can concern great many various issues and can be of diverse kinds. What are the most important decisions a group makes - it depends on the on the type of this group. As declared above, I focus here on the most important and complex social groups - on groups defined by their relations to states (or other territorial units). Such groups we can call "societies" - e.g. Polish society, Saxonian society, London society..., and - as suggested in the Introduction - global (world) society.

What decisions have to make societies? Surely: various. But many of them can be grouped together since, in spite of variety of issues resolved by these decisions, they share a form - the form of legal acts (constitutions, bills and the like). Using other words, one could say that law-making is the main type (form) of group decision-making if a society is this group and if this society should develop in a sustainable manner (Kwilinski et al. 2019).

In the context of the issues discussed in this paper, a note on relations between technology and law should be made. The development of technology can be characterized in various ways. In particular, it can be viewed as a process resulting in greater and greater human power over the world (human body and psyche including; let us note that the philosophically interesting and difficult problem of "reflexive power" or "self-power" arises here (Kuzior and Kwilinski 2021)). The ways in which this power is exercised have to be regulated. As a consequence, whole new branches of law arise. Most of them (e.g. space law, computer law etc.) has to have international character. This trend in law is one of those that create new challenges for democracy. 
As for now, only a very general (and thus: very partial) characteristic of democracy has been sketched. Now, a characteristic of a more specific kind is to be given. As formulates it one of the most prominent contemporary theoreticians of democracy, "tendency toward democratic participation arises from...the logic of equality" (Dahl 2015). This "logic" manifests itself in the very simple (and fundamental) rule: one individual - one vote.

A few additional comments should be made. First, the concept of democracy is, as it was said, fundamentally connected with that of equality - with the central concepts of various forms of egalitarianism. (Separately the relations between egalitarianism and individualism should be analyzed; this has to be remained for another occasion.) Just the variety of forms demonstrates how deceptive is the (apparent) simplicity of the concept of equality. Second, however unclear this concept might be, it has played a very important role in the history of last centuries: The American 'Declaration of Independence" (04.07.1776) states that "all men are created equal"; the French "Declaration of the Rights of the Man and of the Citizen" (26.08.1789) is somewhat more specific saying that "men are...equal in rights".

These two documents can regarded as marking symbolically the beginning of the modern trend towards democracy. Third, a number of, so to say, "technical" issues arise. It is rather obvious that some minimal mental capacities should be expected (demanded?) from a person id s/he is to participate in democratic decision-making. On the one hand this issue is related to the developmental psychology (the problem of age and maturity), on the other hand - to psychiatry (the problem of "normalcy"). These brief remarks should but demonstrate that I am aware that with development of democracy many troubles and difficulties are connected. Nevertheless, attempts and efforts oriented at their (incremental and partial) overcoming are meaningful if we regard democracy as an ideal. Since I share this attitude, I am going now to discuss shortly the axiological (ethical etc.) fundamentals of democracy.

Let us return to equality. It is obvious that not all rights can be granted to every (adult and normal) person - for instance the right to drive a car or to teach higher algebra. It is also almost obvious that hard working person should be better paid than an idler. Etc. Etc. But, at least according to the opinion accepted by many persons, medical ambulance should come - in the situations of some types - to every human, irrespective of his or her merits. S/he also should not be humiliated irrespective of being an innocent individual or a criminal... In short, humans are very complex beings characterized by many various attributes (capacities etc.). If viewed from the point of view determined by some attributes they can treated in a not egalitarian way; if seen from the point of view determined by other attributes they should be treated as equal.

Trying to formulate these observations in more abstract terms, I would say that a part of human attributes constitute what could be called "moral person" (or just "person"?), and that just as moral persons we all are equal. 
And just as (moral) persons we are (should be regarded as) equal as to deciding in what society we want to live. It could be said that we are equal if the most fundamental decisions - decisions of moral and not of practical (instrumental) character - are to be made. It should be noted that the problem of dividing decisions (and problems tey are to solve) into fundamental and practical is itself a fundamental problem to be solved by a fundamental decision. - So much can be said now about the first argument.

The second argument is based on the stance known as communitarianism (a stance opposed to libertarianism). According to this view, very generally interpreted, human is a social being: community is a reality which is (should be) for humans not only of instrumental but also of autotelic value. (An analogy with our attitudes toward the Nature could be made: we can regard it as a storage of useful things, or - as a being of its own intrinsic value.) It can be maintained that participating in the process of (re-)constructing the structure (order) of community is an important way of reinforcing one's bonds with it. (This opinion echoes the views of the Ancient Greeks who regarded participation in public/political activity as the most important part of human life.)

The next argument is closely related to the previous one but is of somewhat more instrumental character. To outline it, let us start with a note on the attitudes towards law. Sociological studies demonstrate that these attitudes vary considerably - both in time and space. In particular, in authoritarian societies (or in societies with long authoritarian past) law is most often regarded as imposed "from above" - as a manifestation of the arbitrary power of the state (of the rulers). Such an attitude may result in the social disorganization (if the state is not able or prone to intensify controlling citizens) or - in the strengthening the role played by police and other institutions of state control. - It is obvious and has not to be stressed that neither of these results is socially desirable.

Contrarily, one can expect that participation in the law-making may result in more positive attitudes towards law. For two reasons: First, democratic law-making can be interpreted as a form of the concluding a social contract - contract between equal citizens. Such a contract is likely to be more respected than arbitrary rules established by authoritarian power. Second, there is a positive correlation between quality of law and the respect for law. The phrase "quality of law" could be interpreted as a name for a synthetic index - an index composed of quite a few simple indices. It is neither possible nor necessary even to try only to enlist all such indices. Out of them, I'd like to mention two indices only. One of them can be called "realism of law".

Law, simply (schematically) put, is composed of warrants and prohibitions (and somewhat less importantly - oermissions). It could be said that law (more precisely: the given legal system) is "realistic" if there is "sufficiently high" (cf. comments made above while speaking about global disasteres) probability that people will do what they - 
according to it - should and will not do what they should not. The other index can be called "determinism" or "predictability". Law, if it is actually applied, has various consequences; some of them are intended, some are not; it also happens that the actual consequences are even contrary to the intended ones. In any individual case it is rather impossible that the given law is "realistic"("determinist") or is not. But it can be argued than some mechanism of law-making will be giving us "realistic" ("predictable") law more often than some other mechanisms. I believe that democratic mechanisms result more often in better quality of law than non-democratic ones.

The last (hypo)thesis needs a reservation (qualification). And to formulate it some additional analytical comments on the notion of democracy are necessary. First, of methodological character. For some goals, we can (in regard this notion as dichotomous (here is democracy, there is not). But for some other, we can regard it as being of ordinal type ("this country is more democratic than that one"). Second: it can be said that minimal level of democracy is defined as follows: all members of a group (society) can decide who is to make "substantial" decisions. This condition satisfies any system of representative democracy.

And how we could characterize stronger types (higher levels) of democracy? Two elements (distinct but interrelated) seem to play the crucial role: participation and deliberation (this role is reflected in the existence and importance ot the terms "participative democracy" and "deliberative democracy"(Saward 2003)). Both participation and deliberation would deserve separate analyses (not only conceptual but - first of all - substantial; shortly speaking: the problems of the scope and degree of participation, and of the quality of deliberation). The term "participation" indicates the elements of directness in the given democratic system. And the term "deliberation" describes a mechanism of making decisions by a group of people. The level of democracy is, according to proposed here conception, depends on the le1vel of participation and deliberation.

Approaching the end of this chapter I would like to stress that - roughly speaking - the more participative and deliberative a democratic system is, the more fully the arguments in favor of democracy can be applied.

\section{Impact of information technology (IT) on democracy}

According to the interpretation assumed in this text, democracy can be regarded as a type of collective (group) decision-making. As in the case of any kind of decision-making (be individual, be collective), disposing some relevant information concerning the decision problems is crucial for democracy. And due to the collective character of democratic decision-making, possibility of communication between the members of the group that is to make a decision is a fundamental precondition of democracy. (Goldman 2011) 
As in the case of almost all other human actions, communication and other forms of availing of information use various types of (material) instruments. (Sustein 2011) Thus, I would like to commence this chapter with some remarks on information technologies. (Brey 2009) In it broadest sense of the term, it encompasses all material means being used for storage, retrieving, transmitting and manipulating information. Having assumed this sense of this notion, we can speak about (at least) 5000 years long history of information technologies. Their history (and correspondingly: their types) can be divided into four periods (types): pre-mechanical (till mid- $15^{\text {th }}$ century, mechanical (since the invention of print till mid-19th century), electromechanical (since the invention of telegraph till the mid-20 th century) and electronic (since the invention of computer; not ended yet). My attention will be focused on the fourth period/type - i.e. electronic IT. For this reason I will omit the adjective "electronic": the phrase "information technologies" will be regarded as shortened form of "electronic IT". If other types of information technologies will be mentioned, proper adjectives will be added. Let me also stress that though computers and their networks (in particular: Internet) are the main part of IT, but other technologies such as television/radio and phones should also be regarded as its parts.

In this chapter I am going to consider three different though interrelated problems: In which ways IT actually exerts influence on democracy? In which other ways IT could influence it? And - it which of those possible ways democracy should be influenced?

Before I discuss the relations between information technologies and democracy considered as already existing order, I would like to say some words on the role various types of information technologies can play (have played) in the development of (struggle for) democracy. Without getting into difficult problems discussed in social (cultural) anthropology, we can assume that early societies (hordes, tribes etc.) were relatively democratic (Dahl 2000). This situation started to change dramatically some 5000 years ago: more or less at the same time when the institution of state began to develop and the evolution of writing was initiated. With very few exceptions (of which ancient Greece and, particularly, the ca. 500 B.C.-300 B.C. Athens - is the most important; we owe her the very idea of democracy and its first theoretical analyses) vaarious non-democratic orders had dominated till the last decades of $18^{\text {th }}$ century.

However complex and differentiated are current interpretations of the American (1776) and the French (1789) revolutions, both these historical events are rather commonly regarded as the beginning of the development of modern democracy (democracies). - Of course, this process has had its "ups" and "downs", it sometime accelerated and sometime slowed down... A book would be necessary to present a systematic theoretical analysis of this process (and many-volumes work if it were to contain its both spatially and temporally complete - description). And a large separate paper if the main ideas of such a book were to be presented. However, it is possible to make a few useful points on this issue. Firstly, if we look at the last 250 years or so from a distance, the trend towards democratization is clearly visible. Secondly, a great variety of factors have co-determined this trend; among them - the great development of 
electromechanical and electronic information technologies (both parts and products of subsequent industrial revolutions, resulting from the first - at the turn of $18^{\text {th }}$ and $19^{\text {th }}$ centuries). Thirdly, no - even the most visible - trend should be regarded (at least without separate theoretical argumentation) as a manifestation of a deterministic law. History is rather an interplay of various trends, of which some may be opposite. Thus, we cannot be sure that the trend toward democracy will not reverse, and - in particular that information technologies will always be democracy supportive.

So much for general remarks. I would like to supplement them with three historical observations. First, the role IT (mainly TV) played in the 1989 "Autumn of Nations": the revolutionary processes started in Poland and Hungary. Also in the other countries of the "Soviet bloc" internal situation played key role in these processes. But, on the other hand, there is little doubt that the information about Polish and Hungarian transformation played in those countries "catalyst role", at least. A feedback between political changes should be noted: The IT contributed to the 1989 revolutions, these revolutions resulted in the end of cold war, and the last process made possible reduction/abolition of political control of Internet what allowed its dynamic development in 1990s.

Second: the "Arab Spring" (2010-2012). On the one hand, this historical phenomenon is much more ambiguous than that mentioned in the previous passage: the movements were less successful and its results much more dramatic. On the other hand, the role of IT in those processes - though a subject of some controversies - is regarded as considerable, at least. It is worthwhile to note that the "Spring" was initiated in Tunisia and just in this country conflicts concerned the access to WikiLeaks materials

Third: the rise of anti- and alter-globalization movements (global democracy might be defined as their main goal). As for now, their successes are very limited. But, at least, they succeeded in making globalization a subject of world-wide debates. They also demonstrated that global social movements can develop without large organizational infrastructure: Without Internet these movements could not exist and act. In sum: the fact that IT played in those changes considerable positive role seems to be beyond any serious doubt. So much about IT and struggle for democracy.

The next fragment of this chapter I will begin from noting a simple but important historical fact: The history of modern democracy starts in the second half of the $18^{\text {th }}$ century. It is also the time of Enlightenment - of many interconnected ("interwoven") processes which, viewed as a dynamic whole, can be regarded as a profound cultural revolution. It has had a great impact on the history (cultural, political, economic etc.) of the next centuries - until our times. In particular, just in this epoch the idea of common compulsory education started to be introduced (rather slowly: in quite a few states only in the second half of the $20^{\text {th }}$ century!). There is very little doubt that temporal coincidence with the industrial revolution and with the development of democracy was not incidental. This concidens confirms the intuitively rather obvious conviction that (modern) democracy presupposes a level of cultural competences. This conviction, 
should be, I think, modified and formulated as follows: The minimal level of competences necessary for (effective and rational) participation in democracy is a monotonically increasing function of the complexity of the global system. If so, it could be that cultural competences increase but slower than the complexity of the system, and in result - the gap between necessary and actual competences increases, too (what would have negative consequences for the quality of democracy). To avoid misunderstanding, I would like to underline that the last statement is to be regarded as a sketch of a hypothesis that should be first made more theoretically precise and then empirically tested. And now I would like to supplement this sketchy hypothesis with some further considerations on these issues.

I am convinced that "understanding the world" (explication of this phrase is to be looking for in a branch of philosophy: in epistemology - a task for itself) is very important part of cultural competence. But, though by no means identical with (factual, encyclopedic...) knowledge, without such a knowledge it is impossible. And Internet seems to negatively affect the amount of permanently possessed knowledge, especially in the case of people who have used computer and Internet since their early childhood: Ease of access to information supports conviction that large knowledge does not need be acquired (if it as always "at hand" - in mobile phones). And there is no permanent knowledge without memory. But memory should be developed - by acquiring knowledge. Thus vicious circle seems to be formed: little learning $=>$ weak memory $\Rightarrow$ smaller motivation and weaker ability to learn $\Rightarrow$ little learning...and so on.

So much about knowledge. It is obvious that possession of even large knowledge is not sufficient for "understanding the world". It is also impossible without the ability to analyze the possessed knowledge (to confront various its element, to look for hidden assumptions or not formulated consequences, etc.). But without some traits of character, in particular - without the ability to concentration and without patience - analysis is almost impossible. And, one can suppose, books-based learning helps to develop these traits much more than the Internet-based learning.

In the previous passage I focused on some ways in which information technology influences individuals. Now I am going to pass to the ways IT influences interpersonal communications (the central element of any "high level" democratic system).

At the beginning of world-wide Internet (at the 1990s) the optimistic views on its role in the development of Internet dominated. The development of Facebook (since 2004) and other social media resulted in the gradual change of these views. I am not sure that pessimism has triumphed but that we meet today more pessimism than twenty years ago is, to my perception, easily noticeable. (Fallis 2011)

Let us try to identify the main sources of this change. It seems to me that we should start from the phenomenon known as "filter bubble". This, quite popular today, term was coined by Eli Pariser, an American activist and entrepreneur, and popularized by his best-selling book. Its full title - "Filter Bubble: What the Internet is Hiding from You" 
(Pariser 2011) expresses the main idea of this book. (Let us add at once that such persons as Bill Gates or Tim Berners-Lee declared that they shared Pariser's concerns.) What is the main effect of the rise of filter bubbles? I think that it might be defined as the growth of the number of people possessing "closed" (dogmatic etc.) world views and unwilling to participate in debates with differently-thinking people. It should be stressed that "closed" world views are (most often at least) characterized by tendency toward simplifications (thus, in particular, toward dichotomous/"zero-one" images). It is rather obvious that in the time of increasing complexity of the global system such intellectual attitudes are highly undesirable, if not to say - dangerous.

Not all users of Internet are closed in this or that filter bubble. Some are active on those web portals which are visited by people of different (political, religious, etc.) views. And on such portals confrontations of views can be met quite often. But these confrontations deserve rather the name of "ideological battles" than that of "political (philosophical...) debates": (extreme) emotions dominate any rational argumentation. The ultimate result of such confrontations turns out to be identical with that caused by remaining in a bubble.

The analysis of the impact of IT on democracy could (and should) be much more comprehensive and detailed. But some tentative hypotheses can be formulated already now. They could be formulated as follows: If only the basic (low, minimal) conditions of democracy are taken into account then the impact of IT on democracy can be evaluated rather positively. On the other hand, if we think about the democracy in the "more ambitious" sense of the word (as a mechanism of community-building or of social dialogue) then this impact will be evaluated rather negatively.

To the last statement a stipulation has to be made. This statement evaluates the past and current situation. And what about the future? Two questions should be discussed. First: It is not obvious that the negative impact of Internet on democracy is determined by its inherent traits. Perhaps the social (legal, political, financial, educational...) and not technological factors are responsible? And second: even if technology is responsible should we assume that no technological improvements (improvements from the political/democracy-oriented point of view) are possible? - These questions have to remain open.

\section{Democracy and development of information technology}

This chapter I would like to commence with some remarks on one of the oldest and most fundamental philosophical issues. To indicate this issue it will be convenient to avail of the following three notions: determinism, development, evolution. Any systematic discussion of this notions (being subjects of numerous books) is neither possible nor necessary here: mey remarks will be as brief as possible. The idea of determinism can be formulated so: If an object (be an atom, be the Universe, be a human...) is at a moment of 
time in a particular state, then the set of states in which this object can be found in a future moment is limited (i.e. is smaller than the set of all logically possible states), and the content of this set depends on this very state. The idea of development can be characterized so: some objects are changing - deterministically and directionally (i.e., roughly speaking, oscillatory changes are excluded). And evolution can be understood as a special case of development. The most fundamental types of evolution studied today are: cosmological (evolution of the Universe), biological (evolution of life on the Earth) and socio-historical (evolution of the human civilization/culture). Two complementary opinions are today widely (or even universally) accepted. On the one hand: there is no doubt that virtually all great processes are of evolutionary character, thus are - to a degree - deterministic. On the other hand: the future of many (of all?) of them is - to a degree - open. The real and interesting controversies concern just this degree: what is open and what is not.

Particularly "hot" debates concern the evolution of human society (societies). This is a large and very controversial (ideologically and politically involved) issue which cannot be discussed here - only one its aspect is to be undertaken: In the human civilization (culture) some "areas" ("domains" etc.) - such as religion, science, law, art, etc. - can be distinguished. One of the central questions of historiosophy (i.e. philosophy of history) can formulated as follows: which of these "areas" can be regarded as (relatively) autonomously evolving. Can we speak, for instance, about (autonomous) evolution of religion or of morality? - Various answers have given to such questions.

One of the most important questions of this sort is the one concerning technology. To my knowledge, this question has not been explicitly asked, thus - the more - no answers could have been proposed. Unable to make references to any existing theory, and having no possibility even to sketch my own theory, I have to limit myself to a declaration: I believe that history of technology can be regarded as an evolutionary process. I think also that already now some arguments supporting this hypothesis can be formulated: If history of technology is viewed in a very broad perspective, quite a few trends can be detected; for instance, a trend of increasing complexity of technological instruments and somewhat similar trend of growing "recurrent character" of these instruments (machines to produce machines to produce...), or a trend towards larger and larger technological systems (such as Internet); also a trend towards more and more rational character of creating new technologies (cf. the role of Edison's institute in Menlo Park). The very existence of these trends supports the hypothesis. It seems to be additionally supported if we note that these trends are is some important respects similar to those which are characteristic for biological or even cosmological evolution. So much about evolutionary character of the history of technology. (Wiener 1978)

Now I am going to consider the question about openness of the technological evolution. (Grunwald 2000; Schwab 2016) I tend to think that this evolution is open, thus - to put it in other words - various alternative future "trajectories" of technology development are possible. Two supportive arguments could be formulated here. The first one is based 
upon analogies with other types of evolutions. There is today very little (if any) doubt that all evolutions we have studied are (more or less) open; I do not see any serious reason why technological evolution should be an exception to this rule. The second argument is based on the fact of growing "rational character" of technology creation. Shortly put, it could be said that creation of new technologies can be interpreted as solving technological problems (cf. the above remark on Edison). Therefore, the development of technology depends (among others) on the way in which such problems are defined. The "rational character" of technology creation has another aspect: searching for solutions to technological problems is conducted not by individuals (some rare exceptions be left aside) but by professional teams (or whole institutions/organizations) often very large. For this reason, technology creation needs large financial investments and organizational efforts. In consequence, those who decide about these investments and efforts decide (to a degree, at least) about the directions in which technology is being developed, which should support sustainable development (Kuzior and Lobanova 2020; Kuzior 2010; Przybylska-Czajkowska 2019b)

I would like to end this passage with the following quote: "the nature of the beginning civilization of knowledge will give people almost unlimited possibilities to choose between various technological options - also the suicidal ones" (Wierzbicki 2011) (The author of these words represents a unique combination of competences: he is an expert in electrical engineering and automation, has published may works in these domains but also patented some inventions; he has also very good and wide philosophical knowledge.)

Let us assume that, on the one hand, there has been such a process than can be called "evolution of technology" and, on the other, that this process is open. It is thus possible that, with due care, we could try to control this evolution - to enhance some trends and to weaken others. In this way we have arrived to the area of theoretical reflection and practical actions widely known under the name of Technology Assessment (TA). (Grunwald 2009) Looking from the historical perspective, one could say that TA came into existence (some fifty years ago) as, so to say, reaction to the actual technological developments which raised some serious social concerns. In the 1990s, in Netherlands, new orientation in TA emerged: Constructive Technology Assessment (CTA). The goal of CTA is to involve people who will use the technologies being created into the process of their designing. (Czajkowski 2020; Vrain 2017; Phoenix and Trader 2008)

It seems to me that there are some theoretical (methodological, philosophical) connections between CTA and technology forecasting and that these connections should be strengthened. The common task for the both disciplines could be defined in the following way: studying possible directions of the technological development. These studies should deliver theoretical basis for the science (technology) policy. (Street 1992, Roco et al. 2013) 
It is rather obvious that not all detail problems of the science (technology) policy can be, resolved in the broad, democratic way. On the other hand, assuming some values (declared in the chapter on democracy), one should contend that some problems - of fundamental character - should be in this way decided. (Which problems - it is a separate question. And in which way this very question should be resolved? The theory of democracy seems to be involved into some logical traps.)

I think that there are a few problems concerning scientific (technology) policy that should be decided in maximally democratic way. The problem of the possible and desirable directions of the development of Artificial Intelligence belongs, in my opinion, to this group (Yudkowsky 2008). Some AI researchers, politicians etc. regard those who claim that it is a serious problem as non-competent technophobes. If so, to this group should be included such persons as F. Wilczek (physicist, Nobel prize winner), S. Hawking (prominent physicist/cosmologist), AI researchers from MIT, some business... - one hundred and fifty persons who undersigned and open letter in which it is being said about the end of the human race as a possible consequence of the development of artificial general intelligence (AGI).

Three issues connected with this problem should be briefly discussed here (each of them would deserve a separate paper). First, the global character of the problem: if AGI will be created only at one place, this fact will have - sooner or later - global consequences (the inventors will not be able to hide AGI for a long time). Second, the problem has both mathematical and ethical character (similar to that generated by nuclear energy): what does mean the phrase "very small" if applied to the probability of the end of human race? And third a moral (philosophical, existential) problem: the "end of human race" has not to be identical (identified) with its physical destruction; it can mean - as a Polish sociologist suggests - very profound transformation (incidentally, recommended by some transhumanists) of the human nature (Zybertowicz 2015). How profound, if any, such a transformation should be acceptable? Such issues should be decided by a global democratic mechanisms.

Designing such a mechanism (not to say about its practical construction) is a great challenge scientists, politician social movements activist...face already today: according to many experts, the problem of AGI will become real in a few decades. If so, we have still some time. The point is to make a good use of it.

Funding: This research received funding upon the project run by the Department of Applied Social Sciences of the Faculty of Organization and Management of the Silesian University of Technology directional research for the year 2021: 13/020/BK21/0062

Conflicts of Interest: The author declares no conflict of interest.

\section{References}


(Bauer 2009) Bauer, Johannes M., and Paulien M. Herder. Paulien. 2009. Designing Socio-Technical Systems. In Philosophy of Technology and Engineering Sciences Edited by Anthonie Meijers. Amsterdam Elsevier, pp. 601-629

(Bostrom and Cirkovic 2008) Bostrom, Nick and Milan M. Cirkovic. 2006. Introduction. In Global Catastrophic Risks Edited by Nichk Bostrom and Milan M. Cirkovic, pp. 1-30

(Brey 2009) Brey, Philip and Johny Haartz. Philosophy of Computing and Information Technology. 2009 In Philosophy of Technology and Engineering Sciences Edited by Anthonie Meijers. Amsterdam Elsevier, pp. 1341-1409

(Caplan 2008) Caplan, Bryan. 2008. The totalitarian threat In Global Catastrophic Risks Edited by Nichk Bostrom and Milan M. Cirkovic, pp. 504-519

(Courpasson 2017) Courpasson, David 2017. Management as a Practice of Power. In The Oxford Handbook of Management. $\quad$ Edited by Adrian Wilkinson et al. Oxford: Oxford University Press, pp. 367-385

(Czajkowski 2020), Czajkowski, Waldemar. 2019. Social Utopias and Engineering Design. In Ed. Katarzyna Midor, Multidisiplinary Aspects of Production Engineering. Social Sciences Part 2. Warszawa: Sciendo

(Dahl 2015) Dahl, Robert A. 2015. On Democracy. Yale: Yale University Press

(Fallis 2011) Fallis, Don. 2011. Wikiepistemology. In Social Epistemology. Edited by Alvin I. Goldman and Denis Whitecomb. Oxford: Oxford University Press, pp. 297-313

(Gell-Mann 1994) Gell-Mann, Murray. 1994. The Quark and Jaguar. Adventures in the Simple and the Complex.New York: W.H. Freemann aand Company

(Goldman 2011) Goldman, Alvin. 2011. A Guide to Social Epistemology In Social Epistemology. Edited by Alvin I. Goldman and Denis Whitecomb. Oxford: Oxford University Press, pp. 11-37

(Grunwald 2000) Grunwald, Armin. 2000. Technik fuer die Gesellschaft won morgen. Moeglichkeiten und Grenzen gesellschaftlicher Technikgestaltung Frnkfurt/New York: Campus Verlag

(Grunwald 2009) Grunwald, Armin. 2009. Technology Assessment: Concepts and Methods. In Philosophy of Technology and Engineering Sciences Edited by Anthonie Meijers. Amsterdam: Elsevier, pp. 1103-1146

(Hanson 2008) Hanson, Robin 2008. Catastrophe, social collapse, and human extinction.In Global Catastrophic Risks. Oxford: Oxford University Press,pp. 363-378

(Jones 2008). Jones, Geoffrey 2008. Globalization. In The Oxford Handbook of Business History. Editedy by Geoffrey Jones and Jonathan Zeitlin, pp.141-170

(Kwilinski et al. 2019). Kwilinski, Aleksy, Volodymyr Tkachenko, Aleksandra Kuzior, Transparent cognitive technologies to ensure sustainable social development. Journal of Scurity and Sustainability Issues, 2019, 9(2), pp.561-570, doi: 10.9770/jssi.2019.9.2(15)

(Kuzior 2010) Kuzior, Aleksandra 2010. Polskie i niemieckie doświadczenia w projektowaniu i wdrażaniu zrównoważonego rozwoju [Polish and German Experiences in Planning and Implementtion of Sustainable Development] Problemy Ekorozwoju Problems of Sustainable Development, 5: 81-89 [in Polish]

(Kuzior and Kwilinski 2021) Kuzior, Aleksandra, Aleksy Kwilinski. 2021. Zarządzanie refleksyjne - prolegomena. In Wybrane apekty komunikacji i zarządzania w turbulentnym środowisku Eds. Aleksandra Kuzior, Dariusz Krawczyk. Katowice: Wydawnictwo Naukowe "Śląsk"

(Kuzior and Lobanova 2020) Kuzior, Aleksandra, Alla Lobanova. 2020. Tools of Information and Communication Technologiesin in Ecological Marketing under Conditions of Sustainable Development, Journal of Risk and Financial Management 2020, 13(10), 238, https://doi.org/10.3390/jrfm13100238

(Kuzior and Zozul'ak 2019) Kuzior, Aleksandra, Jan Zozul'ak. 2019. Adaptation of the Idea of Phronesis in Contemporary Approach to Innovation. Management Systems in Production Engineering. 27(2): 84-87

(Lomborg 2007) Lomborg, Bjorn. 2007. Cool It. The Sceptical Environmentalist's Guide to Global Warming. New York: Alfred A. Knopf (Lundstrom and Wong 2013) Lundrstom, Mark and H.-S. Philip Wong. 2013. Convergence Platforms: Foundtional Sciences and Technology Tools. In: Michail C. Roco et al. Convergence of Knowledge, Technology and Society. Beyond Convergence of Nano-Bio-Info-Cognitive Technologies. Heidelberg:Springer, pp.1-52 
(Mainzer 2004) Mainzer, Klaus. 2004. Thinking in Complexity. The Computational Dynamics of Matter, Mind, and Mankinf. Berlin: Springer

(Parizer 2011) Parizer, Eli. 2011. Filter Bubles:What the Internet is Hiding from You. New York: Penguin Press

(Phoenix and Trader 2008) Phoenix, Chris and Mike Trader. 2008. Nanotechnology as global catastrophic risk In Global Catastrophic Risks Edited by Nichk Bostrom and Milan M. Cirkovic, pp. 481-503

(Przybylska-Czajkowska 2019a). Przybylska-Czajkowska Barbara 2019. Human rights - sustainability - corporate social responsibility. Part I: Some remarks on human rights. In Organization and Management. Scientific paper no, 141, pp. 319-330

(Przybylska-Czajkowska 2019b)

Przybylska-Czajkowska Barbara 2019. Human rights - sustainability - corporate social responsibility. Part II: Some remarks on sustainability. In Organization and Management. Scientific paper no, 141, pp. 331-344

(Przybylska-Czajkowska 2019c) Przybylska-Czajkowska Barbara. 2019. Human rights - sustainability - corporate social responsibility. Part III: Some remarks on corporate social responsibility. In Organization and Management. Scientific paper no, 141, pp. 345-358

(Roco et al. 2013) Roco, Mihail C. et al. . 2013. Innovative and Responsible Governance of Converging Technologies. In: Michail C. Roco et al. Convergence of Knowledge, Technology and Society. Beyond Convergence of Nano-Bio-Info-Cognitive Technologies.

Heidelberg:Springer, pp. 433-492

(Saward 2003) Saward, Michael. 2003 Democracy.Cambridge: Polity Press

(Scholte 2005) Scholte, Jan Aart. 2005. Globalization. A Critical Introduction. rev. ed. Palgravee Macmillan Houndmills New York (Schwab 2016) Schwab, Klaus. 2016. The Fourth Industrial Revolution. Cologne: World Economic Forum

(Sclove 1995) Sclove, Richard E. 1995. Democracy and Technology New York London The Guilford Press

(Stern 2009) Stern, Nicholas 2009. The Global Deal. Climate Change and the Creation of a New Era of Progress and Prosperity. New York: Public Affairs

(Street 1992) Street, John. Politics and Technology. 1992. New York London : The Guilford Press

(Sustein 2011) Sunstein, Cass. 2011. Deliberating Groups versus Prediction Market (or Hayek's Challenge to Habermas). In Social Epistemology. Edited by Alvin Goldman and Denis Whitecomb. Oxford: Oxford University Press

(Tom et al. 2013) Tom, Bruce et al. 2013. . Convergence Platforms: Earth-Scale Systems. In: Michail C. Roco et al. Convergence of Knowledge, Technology and Society. Beyond Convergence of Nano-Bio-Info-Cognitive Technologies. Heidelberg:Springer, pp. 95-138

(Vrain 2017) Vrain, Thierry. 2017. The gene revolution and the future of agriculture. In Routledge Handbook of the History of Sustainability. Edited by Jerremy L. Caradonna, pp. 409-417

(Wierzbicki 2011) Wierzbicki Andrzej P. . 2011. Technen: Elementy niedawnej historii technik informacyjnych i wnioski naukoznawcze Warszawa: Polska Akademia Nauk Komitet Prognoz „Polska 2000 Plus.”

(Wiener 1978) Winner, Langdon. 1978. Autonomous Technology. Technics-out-of-Control as a Theme in Political Thought. Cambridge (Mass.): The MIT Press

(Yudkowsky 2008a) Yudkovky, Elizar. 2008. Cognitive biases potentially affecting judgement of global risks. In Global Catastrophic Risks Edited by Nichk Bostrom and Milan M. Cirkovic, pp. 91-119

(Yudkowski 2008b) Yudkovsky 2008 Artificial intelligence as positive and negative factor in global risk. In Global Catastrophic Risks Edited by Nichk Bostrom and Milan M. Cirkovic, pp. 308-345

(Wilczek 2008) Wilczek, Frank. 2008. Big troubles, imagined and real. In Global Catastrophic Risks Edited by Nichk Bostrom and Milan M. Cirkovic, pp. 1-30

(Willis 2008) Willis, Christopher. 2008. Evolution theoryand the future of humanity In Global Catastrophic Risks Edited by Nichk Bostrom and Milan M. Cirkovic, pp. 48-72

(Zeitlin 2007) Zeitlin, Jonathan. 2007. The Historical Alternatives Approach. In The Oxford Handbook of Business History. Editedy by Geoffrey Jones and Jonathan Zeitlin, pp.120-140 
(Zybertowicz 2015) Zybertowicz, Andrzej. 2015. Samobójstwo Oświecenia? Jak neuronauka i nowe technologie pustosza ludzki świat Kraków Wydawnictwo Kasper 